\title{
Lymph Node Mapping
}

National Cancer Institute

\section{Source}

National Cancer Institute. Lymph Node Mapping. NCI Thesaurus. Code C18210.

Lymph Node mapping, also known as sentinel lymph node (SLN) mapping is a procedure in which a radioactive tracer and a blue dye is injected around the tumor site. These two substances travel from the tumor and drain into the sentinel, or main, lymph node.

Together they provide a marker for the location and presence of a sentinel lymph node, allowing discovery of minute metastases areas. 